\title{
Calibration of the Nickel Dimethylglyoxime Spectral Shift at Pressures to 20 Kilobars for Use in Spectroscopic Pressure
}

\section{Measurement}

\author{
Helen W. Davies* \\ Institute for Materials Research, National Bureau of Siandards, Washington, D.C. 20234
}

(October 28, 1967)

\begin{abstract}
A method for incorporating solid nickel dimethylglyoxime in a liquid enclosed by a gasket in the diamond-anvil high pressure cell is described. A calibration curve relating the spectral shift of the nickel dimethylglyoxime visible absorption band to the known freezing pressures of 14 liquids has been obtained. The equation for the calibration line is $\Delta \bar{\nu}=-158.9 P+1.82 P^{2}$ where $P$ is expressed in kilobars. The 90 percent confidence band about the calibration curve has been computed, and the curve has been used to determine the room-temperature freezing pressures of acetone and methylcyclohexane.
\end{abstract}

Key Words: Absorption spectra, diamond-anvil cell, high pressure measurement, nickel dimethylglyoxime.

\section{Introduction}

Previous methods for the calibration of high pressure equipment have generally depended upon the use of materials having known pressure-induced transitions, such as bismuth and thallium [1]. ${ }^{1} \mathrm{Ob}$ servation of their solid-solid transitions (e.g., the Bi I-II transition at $25 \mathrm{kbar}$ ) permits the assignment of the corresponding pressure at specific points. This paper describes a method for continuous pressure measurement, based on the change in the spectral properties with pressure of nickel dimethylglyoxime $\left(\mathrm{Ni}(\mathrm{DMG})_{2}\right)$. Pressure-dependence of the position of the visible absorption band $\left(\bar{\nu} \approx 18900 \mathrm{~cm}^{-1}\right)$ of solid $\mathrm{Ni}(\mathrm{DMG})_{2}$ has been reported [2]. In addition to the large red shift in the spectrum with pressure, this material has further advantages for use in pressure measurement in that it is easily prepared, it is insoluble in most liquids, and the spectral band is relatively sharp. A method for incorporating this material in a liquid in a high-pressure vessel is described, and a calibration curve relating the observed spectral shifts to known hydrostatic pressures is given. The pressure data employed are the known freezing pressures of various liquids. The curve is then used to determine the room-temperature freezing pressures

\footnotetext{
*Present address: 8309 Woodhaven Blvd., Bethesda, Md. 20034.

1 Figures in brackets indicate the literature references at the end of this paper.
}

of two other liquids. The 90 percent confidence band about the calibration curve has been determined and it will be seen that the principal disadvantage of this method of pressure measurement is the considerably lower precision with which pressures can be assigned as compared with the precision of piston or manganin gages. However, the spectroscopic method is particularly useful for measurements in high pressure optical devices such as the diamond-anvil cell, where other methods are not easily used.

\section{Experimental Procedures}

$\mathrm{Ni}(\mathrm{DMG})_{2}$ was prepared by the method of Yamada and Tsuchida, by the reaction of nickel sulfate and dimethylglyoxime, followed by recrystallization of the product from chloroform [3]. Liquids used either were from fresh supplies of spectro grade material or were distilled to constant boiling point just prior to use.

The high pressure equipment used for these measurements was the diamond-anvil high pressure cell [4]. Liquids were contained in the cell with metal gaskets. The preparation of these gaskets has been described [5]. The selection of the metal to be used for a measurement depended upon the maximum pressure range to be reached. The spectral data were obtained with a microscope spectrophotometer, an instrument particularly well suited to investigations of the small samples in the diamond cell [6]. 
The methods used for the preparation of a sample for measurement and for the determination of the spectral shift at the freezing pressure of the liquid are as follows. First, a gasket was prepared and cleaned. Then, with the gasket out of the cell, finely ground $\mathrm{Ni}(\mathrm{DMG})_{2}$ or a mixture of $\mathrm{Ni}(\mathrm{DMG})_{2}$ and an inert solid was placed in the cell and pressure was applied to obtain a thin film of the material between the diamond anvils. The cell was then opened and the large diamond cleaned. With both anvils now out of the cell, viewing through a microscope and using a pointed instrument, a small section of the $\mathrm{Ni}(\mathrm{DMG})_{2}$ film adhering to the small diamond surface was transferred to the center of the large diamond surface. The small diamond was then cleaned, again placed in the cell, and the gasket properly positioned on it. The liquid was added and the cell quickly assembled. In this way the bit of $\mathrm{Ni}(\mathrm{DMG})_{2}$ film on the face of the large diamond was trapped in the liquid enclosed between the diamond anvils by the gasket in the cell.

Alternatively, the small diamond could first be placed in the cell and the gasket positioned on it. The piece of $\mathrm{Ni}(\mathrm{DMG})_{2}$ film could then be placed in the hole in the gasket onto the small diamond surface, the liquid added and the cell assembled, with the same result as above.

When a number of measurements were contemplated, the general practice was to transfer several pieces of $\mathrm{Ni}(\mathrm{DMG})_{2}$ film from a single film preparation to a glass slide where they could be reserved for later use, being transferred to the diamond anvil surfaces as needed. This eliminated the necessity of pressing a new film for each measurement.

The assembled cell was then positioned for viewing the enclosed sample with a microscope. The pressure was increased to completely freeze the liquid and then slowly and carefully decreased to melt most of the crystals. The pressure was then increased sufficiently to grow the remaining crystals slightly in order to ensure that equilibrium between solid and liquid was attained. It was this point of solid-liquid equilibrium that was taken as the freezing point of the liquid, and the spectrum of the $\mathrm{Ni}(\mathrm{DMG})_{2}$ was recorded. It was the general practice then to decrease the pressure to allow the solid to melt completely, to refreeze the liquid, and to obtain the condition of solid-liquid equilibrium a second time. Having thus obtained two (or more) measurements of the position of the $\mathrm{Ni}(\mathrm{DMG})_{2}$ absorption band peak at the liquid freezing pressure, the pressure was released and the position of the absorption band peak at 1 atm pressure recorded. In many instances the cell was disassembled before this final measurement to ensure that no residual pressure was applied to the specimen. The ambient temperature was recorded for each measurement. It was in this way that the data for the calculation of

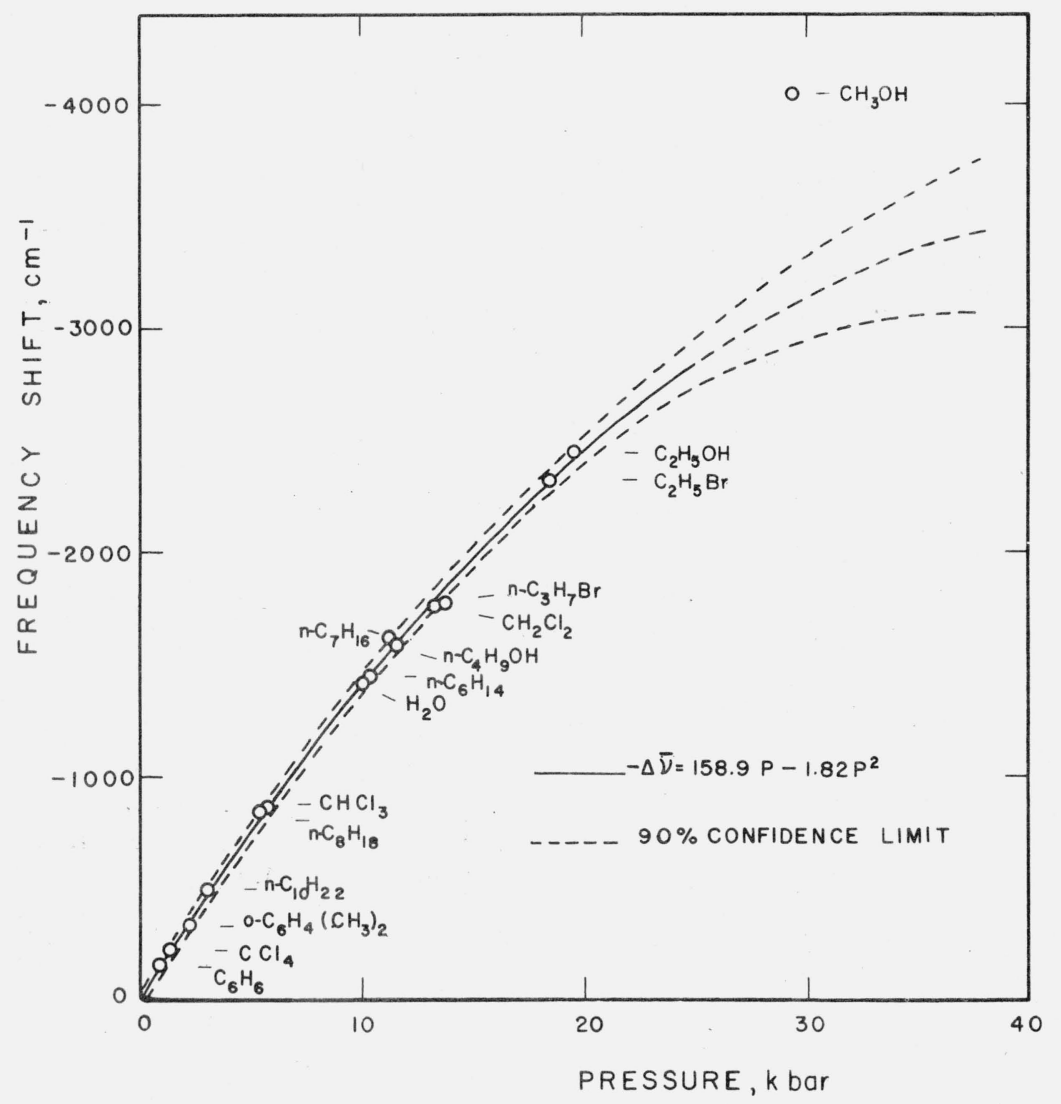

Figure 1. Measured shift of the Ni(DMG) absorption band at the freezing pressures of various liquids at room temperature. 
the absorption band shift, $\Delta \bar{\nu}$, corresponding to the freezing pressure for each liquid were obtained.

It was found that either finely ground pure $\mathrm{Ni}(\mathrm{DMG})_{2}$ or a finely ground mixture of $\mathrm{Ni}(\mathrm{DMG})_{2}$ and an inert solid such as sodium chloride or silver chloride could be used interchangeably for the determination of spectral shifts. The latter, specifically a mixture with sodium chloride, was preferred because when pressed between the diamond anvils it gave the most-easilytransferred films. Pure Ni(DMG) $)_{2}$ films were somewhat brittle and tended to break up when removal from the diamond surface was attempted. Values of $\Delta \bar{\nu}$ obtained were found to be the same whether pure $\mathrm{Ni}(\mathrm{DMG})_{2}$ or mixtures in sodium chloride or silver chloride were used. For the measurement on water, where because of its solubility sodium chloride could of course not be used, either pure $\mathrm{Ni}(\mathrm{DMG})_{2}$ or $\mathrm{Ni}(\mathrm{DMG})_{2}$ in silver chloride was used. In the course of this work several different batches of $\mathrm{Ni}(\mathrm{DMG})_{2}$, prepared as previously described, were used. $\Delta \bar{\nu}$ values obtained for any liquid were reproducible when a different sample of $\mathrm{Ni}(\mathrm{DMG})_{2}$ was used.

\section{Results}

The experimental spectral band shift data are given in table 1 . It will be noted that each $\Delta \bar{\nu}$ figure is the result of measurements on at least two different samples of liquid. In addition, a number of successive freezing point measurements were made with each sample, to determine the reproducibility for the sam- ple. The freezing pressure data are from Bridgman's work, expressed here in kilobars. ${ }^{2}$ As indicated in table 1, where possible, i.e., where sufficient pressuretemperature information was given in the original reference, these freezing pressure data are for the same temperature as that at which the liquid was studied in these experiments.

For all of the liquids except water the Ni(DMG) 2 was diluted with sodium chloride ( $20 \%$ Ni(DMG) 2 by weight). For the measurements on water $\mathrm{Ni}(\mathrm{DMG})_{2}$ $(7 \%)$ in silver chloride was used.

In figure 1 are plotted the data given in table 1 .

The equation of the best line through the experimental points has been derived by the method of least squares, using the OMNITAB program POLYFIT [12]. It was found that a quadratic equation fitted the data quite well, except for the methanol point $\left(\Delta \bar{v}=-4040 \mathrm{~cm}^{-1}, P=30 \mathrm{kbar}\right)$. Bridgman was able to freeze methanol only once and he noted furthermore that on that one occasion the freezing was very sluggish [11]. This point was therefore omitted from the fitting process. When this was done, the least squares values for $b$ and $c$ in the equation $\Delta \bar{\nu}=b P+c P^{2}$ were:

$$
\begin{aligned}
& b=-158.9 \\
& c=+1.82,
\end{aligned}
$$

for $P$ expressed in kilobars. (A constant term was first included. As expected it turned out to be nonsignificant.

\begin{tabular}{|c|c|c|c|c|c|c|c|}
\hline Liquid & $\begin{array}{c}\text { Tempera- } \\
\text { ture of } \\
\text { measurement }\end{array}$ & $\begin{array}{l}\text { Freezing } \\
\text { pressure }\end{array}$ & $\begin{array}{l}\text { Tempera- } \\
\text { ture }\end{array}$ & $\begin{array}{l}\text { Refer- } \\
\text { ence }\end{array}$ & $\begin{array}{c}\text { Mean } \\
\text { measured } \Delta \bar{\nu}\end{array}$ & $\begin{array}{c}\text { Sample } \\
\text { standard } \\
\text { deviation } \\
\Delta \bar{\nu}\end{array}$ & $\begin{array}{c}\text { Number of } \\
\text { samples }\end{array}$ \\
\hline & ${ }^{\circ} \mathrm{C}$ & kbar & ${ }^{\circ} \mathrm{C}$ & & $\mathrm{cm}^{-1}$ a & $\mathrm{cm}^{-1}$ & . \\
\hline 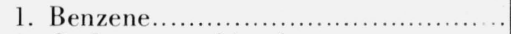 & 29 & 0.834 & 29 & $(7)$ & -155 & 20 & 7 \\
\hline 2. Carbon tetrachloride...$\ldots \ldots \ldots \ldots \ldots \ldots \ldots$ & 28 & 1.383 & 28 & ( 7 ) & -227 & 20 & 11 \\
\hline 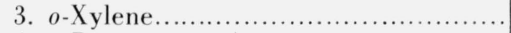 & 28 & 2.256 & 25 & $(8)$ & -338 & 8 & 3 \\
\hline 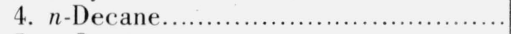 & 28 & 2.991 & 25 & $(8)$ & -490 & 0 & 3 \\
\hline 5. $n$-Octane................... & 25 & 5.403 & 25 & $(8)$ & -845 & 27 & 6 \\
\hline 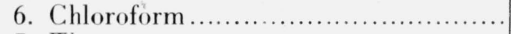 & 27 & 5.541 & 27 & $(7)$ & -852 & 13 & 5 \\
\hline 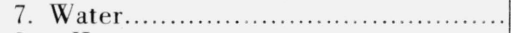 & 28 & 10.052 & 28 & (9) & -1417.5 & 15 & 4 \\
\hline 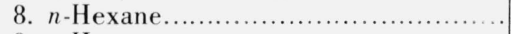 & 28.5 & 10.395 & 30 & $(10)$ & -1433 & 46 & 3 \\
\hline 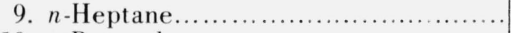 & 27.5 & 11.229 & 25 & $(8)$ & -1610 & 0 & 2 \\
\hline 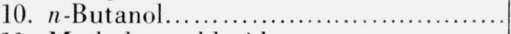 & 27 & 11.572 & 27 & (11) & -1580 & 0 & 2 \\
\hline 11. Methylene chloride................. & 30 & 13.337 & 30 & (11) & -1750 & 0 & 3 \\
\hline 12. $n$-Propyl bromide ........................ & 25 & 13.729 & 25 & (11) & -1770 & 0 & 2 \\
\hline 13. Ethyl bromide...$\ldots \ldots \ldots \ldots \ldots \ldots \ldots \ldots \ldots$ & 27 & 18.437 & 27 & (11) & -2315 & 7 & 2 \\
\hline 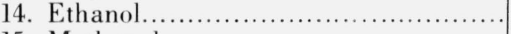 & 25 & 19.613 & 25 & (11) & -2450 & 14 & 2 \\
\hline 15. Methanol............................. & 25 & b 29.420 & 25 & $(11)$ & -4040 & 14 & 2 \\
\hline
\end{tabular}

TABLE 1. Shift of the Ni(DMG) $)_{2}$ absorption band at known liquid freezing pressures

a $\bar{\nu}_{0} \sim 18900 \mathrm{~cm}^{-1}$.

b This value for the freezing pressure of methanol appears to be considerably too low and was not employed in any calculations.

${ }^{2}$ Recent experiments indicate that the pressures assigned by Bridgman to the mercury freezing point and the bismuth transition and then used by him as fixed points in the cali. bration of manganin pressure gauges are about 1 percent low (S. E. Babb. Jr., in High Pressure Measurement, A. A. Giardini and E. C. Lloyd, Eds. (Butterworths, Washington,
D.C. 1963), p. 115). Therefore the liquid freezing pressures determined by Bridgman and used here are likely to be approximately 1 percent low. An increase of 1 percent in the pressures would give the following equation for $\Delta \bar{\nu}: \Delta \bar{\nu}=-157.3 P+1.78 P^{2}$. The change in the equation are less than the standard errors of the $b$ and $c$ coefficients given below. 
Theoretically for $P=0$, one must have $\Delta \bar{\nu}=0$. The fit was then repeated assuming a zero intercept.) The standard errors of the $b$ and $c$ coefficients were 3.3 and 0.21 , respectively. The standard error of scatter about the fitted curve was 36 , which was determined with 12 degrees of freedom. This equation $(\Delta \bar{\nu}=-158.9$ $\left.P+1.82 P^{2}\right)$ was used to obtain the calculated curve of $\Delta \bar{\nu}$ versus $P$ shown in figure 1 .

The 90 percent confidence band about the calibration line, also shown in figure 1, was obtained by computing

$\Delta \bar{\nu} \pm t .90 \sqrt{\left(\text { estimate of } \sigma^{2}\right)+(\text { estimate of variance of } \Delta \bar{\nu})}$

where:

$\Delta \bar{v}$ is the value of $\Delta \bar{v}$ computed for a $P$, using the fitted equation; $t_{.90}$ is Student's " $t$ " for a confidence coefficient of 90 percent, for $12 \mathrm{deg}$ of freedom; $\sigma^{2}$ is the variance of the error in measuring the future $\Delta \bar{\nu}$. increase the pressure until the anticipated phase change has been seen to occur.

The experimental data for the shift of the $\mathrm{Ni}(\mathrm{DMG})_{2}$ absorption band $\left(20 \% \mathrm{Ni}(\mathrm{DMG})_{2}\right.$ in $\left.\mathrm{NaCl}\right)$ are given below:

\begin{tabular}{c|c|c|c}
\hline \hline & $\begin{array}{c}\text { Mean } \\
\text { measured } \\
\Delta \bar{\nu}\end{array}$ & $\begin{array}{c}\text { Standard } \\
\text { deviation }\end{array}$ & $\begin{array}{c}\text { Number of } \\
\text { samples }\end{array}$ \\
\cline { 2 - 4 } & $\begin{array}{c}\left(\mathrm{cm}^{-1}\right) \\
\left(\mathrm{cm}^{-1}\right)\end{array}$ & 4 \\
$\begin{array}{c}\text { Acetone ........... } \\
\begin{array}{c}\text { Methyl- } \\
\text { cyclohexane... }\end{array}\end{array}$ & -1335 & 6 & 4 \\
\hline
\end{tabular}

Using the calibration curve, the following freezing pressure assignments can be made:

\begin{tabular}{|c|c|}
\hline Acetone........... & $9.35 \mathrm{kbar} \pm 0.50 \mathrm{kbar}$ \\
\hline $\begin{array}{l}\text { Methyl- } \\
\text { cyclohexane.. }\end{array}$ & $11.10 \mathrm{kbar} \pm 0.55 \mathrm{kbar}$ \\
\hline
\end{tabular}

Now we have:

$$
\text { Variance of } \begin{aligned}
\hat{\Delta} \bar{\nu} & =\operatorname{Var}\left(b P+c P^{2}\right) \\
& =P^{2} \operatorname{Var}(b)+P^{4} \operatorname{Var}(c)+2 P^{3} \operatorname{Cov}(b, c) \\
& =P^{2}\left\{\operatorname{Var}(b)+[2 \operatorname{Cov}(b, c)] P+\operatorname{Var}(c) P^{2}\right\} .
\end{aligned}
$$

In this case the equation for the 90 percent confidence band is

$$
\Delta \hat{\bar{\nu}} \pm 1.78 \sqrt{1296+P^{2}\left[10.7076-1.3371 P+4.513 \times 10^{-2} P^{2}\right]} .
$$

The $\sigma^{2}$ estimate, 1296, is obtained from the standard error of scatter about the fitted curve, which was 36 , and allows for both the experimental error in a measured $\Delta \bar{v}$ and the error due to lack of fit.

\section{Discussion}

The calibration curve for the shift of the $\mathrm{Ni}(\mathrm{DMG})_{2}$ visible absorption band as a function of pressure, based on 14 known pressure points, has been obtained. In addition, the 90 percent confidence band about the calibration line has been computed. Use of this curve permits the assignment of pressures corresponding to measured $\Delta \bar{\nu}$ values. The confidence band indicates the limits within which an assigned pressure is known.

The use of the calibration curve can be illustrated with the determination of the room-temperature freezing pressures of two liquids: acetone and methylcyclohexane. Bridgman noted the freezing of acetone but was unable to obtain a sample of sufficient purity to make an accurate determination of the freezing pressure [7]. He also studied methylcyclohexane and reported the liquid-solid transition not reproducible [8]. No difficulty in freezing methylcyclohexane was encountered here, largely because the design of the diamond cell permits the visual observation of the sample and the investigator can simply continue to
The \pm values represent the 90 percent confidence intervals.

As was stated earlier, in the determination of the best equation for the calibration curve it was found that a satisfactory fit to the experimental data could be had by excluding the point for methanol. On examining the curve thus obtained (fig. 1), it is readily noted that a spectral band shift of $-4040 \mathrm{~cm}^{-1}$, the shift measured for methanol at its freezing point, would correspond to a pressure much greater than the value of $30 \mathrm{kbar}$ reported by Bridgman [11]. It is suggested therefore that the room-temperature freezing pressure of methanol is not $30 \mathrm{kbar}$, but that on the basis of the experimental data presented here, it is not less than 38 kbars. This estimate is based on linear extrapolation of the curve of figure 1 from the highest experimental points. The maximum in this curve is not meaningful but is a fictitious maximum imposed by the polynomial used to fit the data. In as much as the curvature is positive the linear extrapolation is not expected to overestimate the freezing point.

As mentioned earlier, the shift of the visible absorption band of $\mathrm{Ni}(\mathrm{DMG})_{2}$ with pressure has been reported by Zahner and Drickamer [2]. It should be noted however that, within the range of our experiments, the pressures given by these authors for any 
$\Delta \bar{\nu}$ are not in agreement with the results of the measurements made in this laboratory. In fact, up to our highest measured $\Delta \bar{\nu}$ for which the pressure is known $\left(-2450 \mathrm{~cm}^{-1}\right)$, their pressures are about 50 percent greater than our values. The freezing point data from Bridgman on which a number of our pressure points have been based were determined by him under true hydrostatic conditions. The present data also were obtained under purely hydrostatic conditions, while those of Zahner and Drickamer were not. Therefore, it seems that in this range the nonhydrostaticity might contribute to an overestimate of the pressure by about 50 percent.

The author is indebted to J. Mandel for aid in the statistical analysis of the data and to C. E. Weir for many helpful comments and suggestions.

\section{References}

[1] F. P. Bundy, in Modern Very High Pressure Techniques, p. 18, R. H. Wentorf, Jr., Ed. (Butterworth, Inc., Washington, D.C., 1962)

[2] J. C. Zahner and H. G. Drickamer, J. Chem. Phys. 33, 1625 (1960).

[3] S. Yamada and R. Tsuchida, Bull. Chem. Soc. Japan 26, 489 (1953).

[4] C. E. Weir, E. R. Lippincott, A. Van Valkenberg, and E. N. Bunting, J. Res. NBS 63A (Phys. and Chem.), No. 1, 55 (1959).

[5] C. E. Weir, S. Block, and G. Piermarini, J. Res. NBS 69C (Engr. and Instr.), 275 (1965).

[6] H. C. Duecker and E. R. Lippincott, Rev. Sci. Instr. 35, 1108 (1964).

[7] P. W. Bridgman, Phys. Rev. 3, 153 (1914).

[8] P. W. Bridgman, Proc. Am. Acad. Arts Sci. 77, 129 (1949).

[9] F. W. Bridgman, Proc. Am. Acad. Arts Sci. 47, 441 (1911).

[10] P. W. Bridgman, Proc. Am. Acad. Arts Sci. 61, 57 (1926).

[11] P. W. Bridgman, Proc. Am. Acad. Arts Sci. 74, 399 (1942).

[12] J. Hilsenrath et al., OMNITAB, A computer program for statistical and numerical analysis, p. 113, NBS Handbook 101 (U.S. Government Printing Office, Washington, D.C. 20402).

(Paper 72A2-490) 